\title{
Innovation Management of Enterprises with Scientific and Technological Activities of Some Asian Countries and Lessons for Vietnam
}

\author{
Nguyen Huu Xuyen', Tran Vu Tuan Phan², Tran Xuan Bach², \\ Nguyen Quoc Hung ${ }^{2}$ \\ ${ }^{1}$ National Institute of Patent and Technology Exploitation, Vietnam \\ ${ }^{2}$ Vietnam Institute of Science Technology and Innovation, Vietnam \\ Corresponding Author: Nguyen Huu Xuyen
}

DOI: https://doi.org/10.52403/gijash.20220102

\begin{abstract}
Innovation management plays an important role in enhancing the competitive position of science and technology-based enterprises, especially for enterprises with scientific and technological activities. This is the foundation and driving force for sustainable economic and social development. In Vietnam, innovation management activities of enterprises have made certain progress in recent years; however, improving the innovation management capacity of enterprises through learning from experience in the form of training (short-term training) is necessary to come up with appropriate solutions to improve capacity. The goal of this article: (i) providing a way to identify enterprises with scientific and technological activities in Vietnam; (ii) on the basis of studying the experience of China and Thailand on innovation management in enterprises, the article gives lessons for Vietnam in developing and implementing a training program (short-term training) on innovation management at enterprises with science and technology activities in the context of the strong fourth industrial revolution.
\end{abstract}

Keywords: Innovation management, enterprise, science and technology

\section{RESEARCH OVERVIEW}

1.1. Enterprises engaged in scientific and technological activities

According to the operational approach, science is a specific form of human activity aimed at perceiving the objective world. This is a form of activity to produce knowledge through discovering the nature of things and creating new things in order to improve and develop the objective world. Science is the field of activity aimed at producing new knowledge of nature, society and thought, including all the conditions and factors of this production (Soviet Philosophical Dictionary, Vietnamese version 1975). French Larousse Dictionary (2002) and Vu Cao Dam (2008) argue that, science is a set of empirically verified knowledge about facts, things, and phenomena that obey a definite law. According to the Law on Science and Technology (2013), science is a system of knowledge about the nature and laws of existence and development of things, natural, social and thinking phenomena. This concept mentioned and emphasized the knowledge system, knowledge production activities and social consciousness form.In terms of economics and in relation to production, technology is considered as a means to carry out the production process, transforming inputs into outputs for desired products and services. The Economic and Social Commission for Asia and the Pacific (ESCAP, 1989) defines technology as systematic knowledge of technical processes for processing materials and information; technology includes the skills, knowledge, 
equipment, methods and systems used in the creation of goods and the provision of services. According to the Organization for Economic Co-operation and Development (OECD) definition: Technology is understood as a set of techniques, which are themselves defined as a set of actions and selection rules that guide the sequential application of such techniques that, according to human knowledge, will achieve a predetermined result in a given situation. According to the Law on Technology Transfer (2017), technology is a solution, process or technical know-how with or without tools and means used to transform resources into products.
According to Allan Afuah (2012), the relationship between science and technology can be understood in three different models:

Model 1- linear model: basic scientific research leads to findings, from these findings lead to applied research, the result of applied research is the invention and that invention is commercialized into a product/service. If in the stage of basic scientific research, knowledge is still general, clear and often encoded in the form of text, in applied research, knowledge has become more specific to the culture and environment of the enterprise, more implicit and often encoded in the product/service.

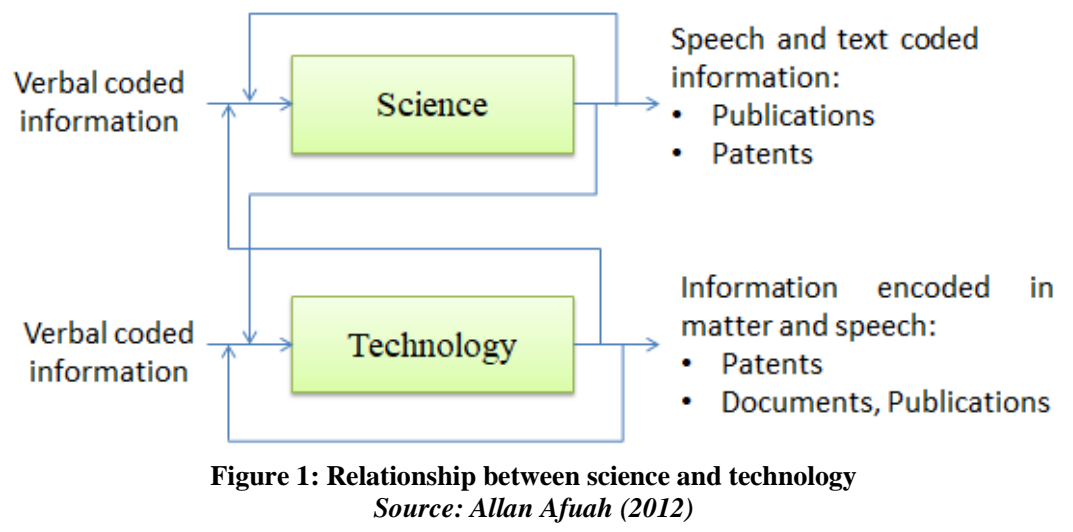

Model 2 - separate model: this model that science and technology are essentially two separate paths, whereby science and technology take place completely independently of each other. In terms of inputs, science has verbally encoded information such as discussions, or presentations, and outputs are publications. Technology also has verbal coded information as input, but output is encoded information in physical form in the form of products/services. Technology also has a by-product - verbally encoded information in the form of instructions on how to use the product/service.

Model 3 - combined model: This model shares the same view with the first model in that both believe that scientific knowledge can be the basis for creating technological knowledge, but disagree with the conclusion that it is only a one-way relationship; at the same time disagree with the second model's assertion that science and technology develop independently of each other. Science and technology depend on each other to exist and complement each other (Figure 1). Science can lead to technology and technology can lead to science. Technological discoveries may require science to gain insights for commercialization. S\&T activities mean activities of scientific research, experimental research and development, technology development, technology application, S\&T services, promotion of initiatives and other creative activities aimed at developing S\&T (Law on Science and Technology, 2013). According to the Enterprise Law (2020), enterprise is an economic organization with its own name, assets, stable transaction office and business registration in accordance with law for the purpose of carrying out business activities. Therefore, enterprises in general and 
enterprises with S\&T activities in particular mostly carry out the production, business and service provision for profit purposes, but there are also enterprises operating without for profit (non-profit).

Thus, an enterprise engaged in scientific and technological activities is an enterprise with at least one of the following manifestations (Figure 2):

Firstly, it is an enterprise that has obtained a certificate of being a science and technology enterprise in accordance with the law.S\&T enterprise is an enterprise that produces, trades and services $S \& T$ in order to create products and goods from the results of scientific research and technological development.A science and technology enterprise must satisfy the following conditions (Decree 13/2019/ND$\mathrm{CP})$ : being an enterprise established, registered for business, organized, managed and operated in accordance with the Law on Enterprises;capable of performing scientific and technological tasks; having a turnover from the production and trading of products formed from scientific and technological results reaching at least $30 \%$ of total revenue.In Vietnam, in 2020, 32 enterprises will be granted S\&T Enterprise Certificates, bringing the total to 538 out of about 3,000 enterprises operating under the S\&T enterprise model.In the context of the impact of the Covid-19 epidemic, S\&T enterprises have made great efforts to adapt and show their pioneering role in researching solutions to prevent and control the epidemic.

Secondly, is an enterprise that has a certificate of high-tech enterprise. High-tech enterprise means an enterprise that manufactures high-tech products, provides high-tech services, and conducts high-tech research and development activities. Hightech enterprise is an enterprise that must satisfy the requirements under the provisions of the Law on High Technology (2008), the provisions of the Law on Investment and the Prime Minister's Decision No. 19/2015/QD-TTg stipulating on criteria for identifying high-tech enterprises. As of January 2021, Vietnam has 46 hi-tech agricultural enterprises; At the same time, in the period 2016-2021, the Program to develop a number of high-tech industries managed by the Ministry of Industry and Trade has had $21 \mathrm{~S} \& \mathrm{~T}$ projects implemented. The products of the projects are highly effective in terms of science and technology, economic efficiency for enterprises participating in the implementation, social efficiency for the community as well as creating a premise for the presiding organization to continue developing technology to provide high-tech products and services.

Thirdly, S\&T enterprise means an enterprise that sets up and forms its own S\&T development fund. The Fund can be organized in one of two forms: establishing an organization without legal status and directly under an enterprise; The Fund organization is not established and the activities are carried out by an employee of the enterprise concurrently (Circular 12/ 2016/TTLT-BKHCN-BTC). Enterprises have the right to autonomy and selfresponsibility in the management and use of the fund for the right purposes for establishing the fund and notify the establishment of a fund to the local state management agency in charge of science and technology where the enterprise's head office is located. According to the General Department of Taxation (2021), in the period from 2015 to 2018, the enterprise's Science and Technology Development Fund used by enterprises is 5,451,857 million VND/13,566,281 million VND Deducted fund (accounting for about $40 \%$ ). Corporations are the units with the largest amount of funds to set up the Fund, however, the rate of using the Fund's funds is still low, unstable over the years, and the difference is large between localities. Some corporations pay much attention to $\mathrm{S} \& \mathrm{~T}$ activities and have effectively used the extracted Fund, but only $60 \%-70 \%$ of the Fund has been deducted (Viettel Military Industry and Telecommunication Group used 2,372 billion VND, equivalent to $60 \%$ 
of the amount set aside for the fund in the period 2016 to 2018, Vietnam Posts and Telecommunications Group...).

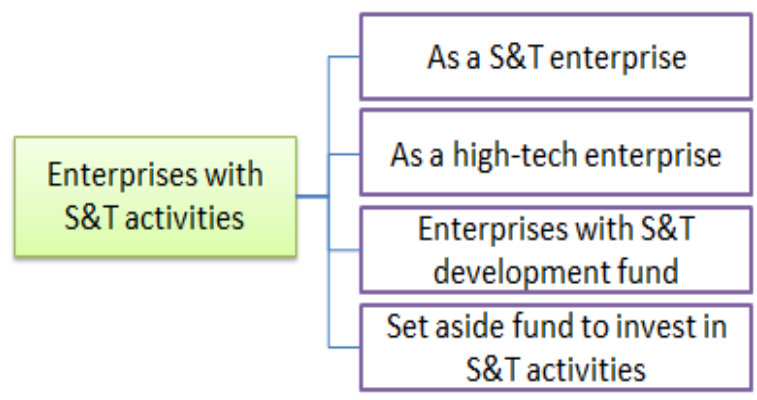

Figure 2: Identification marks of enterprises with S\&T activities

In addition, an enterprise engaged in S\&T activities is an enterprise that has spent investment funds in order to innovate and improve technology levels, and to improve productivity, quality and competitiveness of products and goods; the enterprise's investment in science and technology development is calculated as the actual expenses incurred in relation to the enterprise's production and business activities.

\subsection{Innovation management in enterprises with scientific and technological activities}

Innovation is an important factor to help businesses survive, develop and maintain competitive advantages. Innovation is the commercialization of new elements or combinations of old elements in industrial organizations, involving new materials, new processes, new markets, or new organizational structures (Joseph Schumpeter, 1934). This shows that knowledge is important for innovation. The generated knowledge depends on human resources, especially the quality of the leadership team, which affects the orientations and decisions about $R \& D$ activities in S\&T enterprises (Cunfang, LiaDanping and LibMeiDonga, 2019). According to Katz (2007), innovation is the creation, development and successful implementation of new and unique ideas, including the introduction of new products, processes, and methods for businesses, leading to succeed in production and business activities, create value for stakeholders, promote economic growth and raise income. According to OECD (2005, 2018), innovation is the realization of a completely new product/service or significantly improved in terms of marketing processes, techniques or a new organizational method in production and business activities. To survive and develop, businesses must continuously innovate (William R. Kerr, 2016). Innovation also goes hand in hand with anticipating market needs, providing additional quality or service, organizing efficiently, mastering details, and better controlling costs (EC, 1995; Alexandru Ionescu, 2015; Nguyen Huu Xuyen, 2018). The innovative enterprise is therefore characterized by a high degree of awareness, flexibility and adaptability to fluctuations, the ability to successfully integrate with minimal time and cost.

In Vietnam, the term innovation is commonly used in the Vietnam-Finland Innovation Partnership Program (IPP). Some researchers have used the equivalent word "Innovation" in Vietnamese as "renovation" or "innovation". According to IPP (2013), innovation is the appropriate use of knowledge that adds value to new products and services. At the national level, innovation is associated with the national innovation system (NIS), while at the enterprise level, innovation is the process of creating new products, processes, new methods of organization, management and market access that meet customer requirements and are recognized by society. The innovation process can include a set of interactive activities that are repeated in a non-linear order to achieve an innovation goal. According to the Law on Science and Technology (2013), innovation is the creation and application of achievements, technical solutions, technologies and management solutions to improve the efficiency of economic developmentsociety, improve productivity, quality and added value of products and goods.

Thus, innovation in enterprises with S\&T activities is understood as innovative 
activities of enterprises to carry out scientific research, experimental research and implementation, technology development, application of science and technology, science and technology services, promote initiatives and other creative activities to develop science and technology. According to the National Agency for Science and Technology Information (NASATI, 2018), out of a total of 7,641 enterprises surveyed, there are 4,709 enterprises with innovation (accounting for $61.63 \%$ ), the number of enterprises without innovation is 2,841 enterprises (accounting for $37.18 \%$ ), the number of unidentified enterprises is 91 enterprises (accounting for 1.19\%).

$$
\text { Innovation management in }
$$

enterprises can be a combination of innovation process management and change management. This is the implementation and supervision of the process of transforming ideas or creative processes in an enterprise to create a product or service to bring added value to customers. Innovation management includes not only innovation activities, but also work processes, closely linked S\&T activities such as planning, implementing, operating, maintaining and control (Johnston, 1996). Innovation management will help businesses make appropriate adjustments to the allocation of resources, products, and execution processes to adapt to the uncertainty of the environment; at the same time, the innovation management process depends heavily on the vision, strategic direction of the enterprise, and action plans to realize innovation goals and especially need the determination of senior leaders (Kowang, 2015).This is considered an important part, integrated in the general management of the enterprise. It is the driving factor for the strategic direction of the enterprise, the foundation for establishing policies, objectives, strategies and processes to support the achievement of the enterprise's innovation goals through planning, operating, organizing, controlling, and evaluating performance.
According to ISO 56002 (2019), innovation success is driven by four key drivers:

creative collaboration, innovative thinking (innovation mind-set), systems of work and innovation culture. An innovation management system (IMS) includes the elements and interactions necessary to establish an enterprise's ability to innovate in order to achieve innovation effectively and sustainably. The basic elements of the IMS include (Figure 3):

- Context of the enterprise: the enterprise identifies the internal and external factors that affect the achievement of its innovation goals. These include opportunities, threats, strengths and weaknesses of the business.

- Leadership: senior management demonstrates commitment to the IMS, which establishes an innovation vision, strategy and policy, identify the necessary roles and responsibilities of the relevant departments.

- Planning: from the vision and commitment of senior management, the enterprise identifies specific activities to take advantage of opportunities and avoid risks. Thereby, the enterprise establishes innovation goals and plans to achieve them, such as required resources, organizational model of the enterprise, innovation portfolio.

- Support: the necessary support to set up the IMS, such as human, financial and other resources, awareness, tools and methods, strategy of enterprise's intellectual property management.

- Implementation activities: developing projects, programs or other activities to implement innovation processes in accordance with the wishes and goals of the enterprise.

- Performance evaluation: Evaluate the performance of IMS by relevant innovation indicators according to the vision, plans and goals of the enterprise.

- Improvement: Based on the performance evaluation of the IMS, the 
business makes continuous improvements, in which, focusing on improvement, adjustments related to factors such as context, leadership, planning, support, deployment activities.

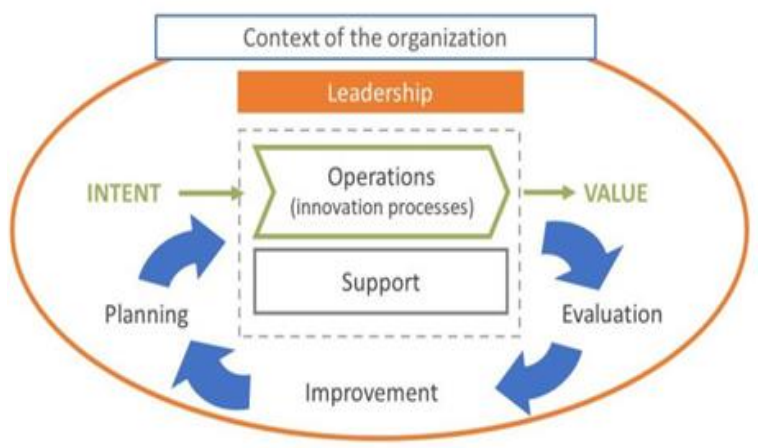

Figure 3: Enterprise innovation management system Source: ISO 56002

In fact, effective IMS is affected by other management systems in the enterprise. Therefore, IMS can be integrated at different levels. IMS is integrated with other management system standards, helping businesses balance the exploitation of existing products, services and activities with the exploration and search for new products and services through innovation activities (Ha Minh Hiep, 2019).Various elements of an enterprise management system, including an IMS, can be integrated into a single management system, also known as an integrated management system.

Thus, innovation management in enterprises with S\&T activities is understood as the process of planning, organizing activities, motivating and controlling resources for innovation activities of enterprises in order to achieve the company's goals in the short, medium and long term in an ever-changing and unpredictable environment.

\section{RESEARCHING METHODS}

To achieve the set objectives, the article mainly uses local research methods. The authors collect, evaluate and select works published in Vietnam and internationally in the form of hard copies and soft copies related to innovation, innovation management of enterprises, innovation management training at enterprises. These studies are reflected in the references of the article.

The use of local research methods through secondary data has certain limitations, which reduces the scientific and comprehensiveness of the article. In order to partially overcome this limitation, the article conducts in-depth interviews with 3 experts working in the fields of science and public to better clarify the assessments, comments and recommendations drawn.

\section{RESEARCHING RESULTS \\ 3.1. Innovation management in Chinese enterprises}

Talent is considered an important foundation for China to achieve its goal of building a prosperous and civilized society by 2020.The Chinese government is gradually transforming the economic growth model from being based mainly on resource consumption to one based on scientific and technological progress. The sustainable development of the national economy and the maintenance of social harmony and stability will be associated with the rapid promotion of the development of highquality human resources. The role of innovation has become increasingly important in economic development, with China spending $1.98 \%$ of GDP on research and development in 2012.

In technology transfer and commercialization activities, in 2013, the Legislative Office of the State Council amended the Law on Promotion of Transfer of Science and Technology Achievements, thereby increasing the number of strategic alliances between industries, research institutes and universities for technological innovation from 4 in 2007 to 146 in 2013. China has used technology demonstration zones, connecting technology supply and demand, and effective innovation management as an important policy tool to spearhead innovation activities, especially innovation in the field of processing and manufacturing (NASATI, 2009).

To date, three science parks have been built in Zhongguancun (Beijing), East 
Lake (Wuhan) and Zhanjiang (Shanghai). Enterprises located in these parks enjoy preferential policies and public support for their activities of adopting and mastering technology and innovation. In addition, the Pearl River Delta Development and Innovation Plan (2008-2020) aims to become a technology and innovation hub in the Asia-Pacific region has also been deployed in China.

The Ministry of Manpower of China has conducted a survey on the current state of talent, along with the implementation of the medium and long-term S\&T development plan (2006-2020). The Central Committee of the Party and the State Council have issued guidelines on promoting the development of talents, especially talents working in enterprises. In which the issue of talent and high-quality human resources is put forward and becomes the focus. In addition, the training program "Starting a business" with the main objective is to raise awareness of the need to create a business and compete in business; master the necessary knowledge about industry, commerce, finance, labor and business activities; at the same time, enhance competitiveness in business operations and management and strategic planning for market development. There are three types of organizations directly participating in the program, namely, Entrepreneurship Training Program Steering Committee, Entrepreneurship Training Program Advisory Council, and job training centers.

Training, promoting R\&D activities and forming $S \& T$ enterprises have been interested by the Chinese Government from a very early age. For example, the "Torch Program" was started in 1988 and since 1996 when China's 9th five-year national development plan was adopted, a number of measures have been taken to support the development of the "Torch Program" in the formation of national S\&T industrial parks, create favorable conditions for the commercialization, industrialization and internationalization of high-tech $\mathrm{R} \& \mathrm{D}$ results; manage and operate the Innovation Fund for S\&T small and medium enterprises. In particular, focus on training and development of human resources; promote and attract quality human resources to ensure and support the commercialization of new and high-tech achievements in organizations, especially in S\&T enterprises. This is one of the main tasks of the "Torch Program" to create generations of human resources and entrepreneurs to develop science and technology, who have good technology training skills, business management and operation skills, creativity in innovation and dare to face challenges and compete in the market.

The formation of support programs through training largely depends on the actual status of R\&D activities at enterprises. Supporting enterprises to improve R\&D capacity has become an important component of China's S\&T development. In addition to the support of the Government, domestic enterprises also increased sharply in $R \& D$ spending with their own capital, foreign enterprises and joint ventures carry out R\&D activities together with enterprises of Hong Kong Macao and Taiwan. To date, ten main industry sectors have been supported, including: information technology, robotics, agriculture, aerospace, marine, railway equipment, clean energy, new materials, biomedical science and medical devices develop smart factories, improve synchronization of production chains.

Developing and implementing training programs for managers of small and medium-sized enterprises and innovative start-ups that are interested by a number of Chinese organizations, specifically: The Shanghai Science and Technology Commission (China) held the forum "Supporting innovation start ups - sharing experiences of Shanghai Innovation Center STIC" (July 2019) to share experiences and knowledge on management policies, development of programs to support training, coaching, support for incubating start-ups, exchange, cooperation, and 
networking of innovative start-ups. According to STIC, innovation start-up activity in China is growing strongly. In addition to supporting incubators, commercializing and transferring scientific and technological achievements, supporting facilities and space for $R \& D$ and trial production activities, STIC also builds and supports the organization of short-term training, consulting and training courses for managers and leaders of start-ups, speeding up capital raising, improving specialized knowledge and legal knowledge in order to reduce risks in business operation.

\subsection{Innovation management in Thai enterprises}

In the economic and social development plan, the Government of Thailandsets research and development (R\&D) spending targets at $1.0 \%$ and $1.5 \%$ of GDP, respectively, in 2018 and 2021. Currently, the total expenditure on (R\&D) of Thailand is at a low average level compared to the world in the range of 0.25 $0.6 \%$ of GDP (up from $0.36 \%$ of GDP in 2011 to $0.63 \%$ in 2016). 2015). In addition, Thailand is implementing the 10-year National Basic Plan on Science and Technology for the period 2012-2021.This plan is designed based on the innovation system at all levels from national, regional and local levels throughout the country with the aims to unify commitments to science, technology and innovation in public institutions and strengthen cooperation between the private sector and academia (Chatri Sripaipan and Yada Mukdapitak, 2007).

Science and technology has an important role for maintaining and improving enterprise's competitive capacity, this has been acknowledged by the nations of the world. Thailand is one of the countries that has achieved many accomplishments in promoting enterprise application of science and technology into production (Nguyen Huu Xuyen, Nguyen Thi Lan Huong, 2017). The Government has created a favorable policy environment through reforming management systems and planning process for science and technology to be able to implement successful innovation: established and supported capacity building of key laboratories in the universities / institutes / the organizations of science and technology, where can create new knowledge through $R \& D$ activities; developed science parks, technical services for links between academic research areas and industrial production zones to support and created favorable conditions for businesses can perform technological innovation activities (OECD, 2011). Thailand has encouraged the development of science and technology for the private sector, such as exemption and reduction of import tax for equipments in service of research, training; tax credits and incentives, allowing accelerated depreciation in the first year for equipment $\mathrm{R} \& \mathrm{D}$ service (up to $40 \%$ ); developing action plans for enhance national competitiveness through performance improvement R\&D capabilities to reform the human technological resources in enter prices to facilitate development of technology in the private sector

Training and improving the quality of human resources for enterprises in technology management and innovation is one of the contents of Thailand's National Strategy on Science and Technology (20042013), through which the Government sets the goal of developing clusters with high technology capacity with aims to support enterprises to receive technology and innovate technology, helping to increase productivity and quality for a number of potential industries (automobiles, software, microchips, textiles, healthcare...), and developing high-quality human resources through policies to attract technology experts from abroad (UNCTAD, 2015).In particular, Thailand has formed a foundation for transfer and innovation activities and has set a goal to become a developed country by 2026. Capacity building in industrial enterprises will contribute to perfecting Thailand's national innovation system with three main actors, namely private 
enterprises, the Government and universities.

The development of business support programs in general and training support for businesses in particular, the Government of Thailand encourages cooperation between the Government, the industrial production sector and universities/ research institutes under the High Quality Human Mobility Program. Along with that, the Government encourages the development of S\&T activities in enterprises in the form of tax exemption and reduction on import of training equipment, tax exemption and accelerated depreciation in the first year for research and development equipment (up to $40 \%$ ); developing action plans to enhance national competitiveness through improving the research and implementation capacity of enterprises and supporting to train highquality human resources under the HighQuality Human Resource Movement Program.

To create a thriving innovation system, Thailand's Office of Science, Technology \& Innovation (2014) has focused on inter-institutional and international cooperation based on knowledge human resources, science and technology infrastructure. Strategies and measures are put in place to develop important factors leading to human resource development programs necessary for the development of enterprises such as (NASATI, 2018): reforming science education through necessary problem-based learning; improving vocational skills through combined learning with work; strengthen cooperation between universities -industry-research institutes through educational activities and improve the motivation of individuals to train and research. In addition, training and improving the quality of human resources are linked with technology transfer and attraction activities. Thailand's technology transfer-related policies are closely integrated in its economic, social and scientific and technological development plans. The development strategies are defined by foundation areas from low to high such as: developing agricultural production in the direction of modernity; developing light industry and outsourcing for foreign countries; investing in heavy industry and increase research and development activities in enterprises with the potential to create export products; developing an economy based on scientific knowledge and innovation.

Up to now, a number of Thai research and training organizations have also developed short-term training programs and organizations for businesses (UNCTAD, 2015). For example, the Asian Institute of Technology (AIT) is considered a reputable research and training institution in developing training programs andin-depth research on technology management and innovation since the 1980s.Many training programs, textbooks, documents and lectures on technology management and innovation of some Asian countries are often cited for typical scientific research works on technology management and innovation in Thailand.

\section{CONCLUSIONS AND RECOMMENDATIONS}

Based on the experience of China and Thailand in innovation management, shortterm training in innovation management, lessons can be learned for Vietnam in developing and implementing innovation management training programs for enterprises with scientific and technological activities as follows:

Firstly, it is necessary to develop and implement a training program on innovation management for enterprises, especially supporting and raising awareness and knowledge for innovative start-ups, small and medium enterprises with S\&T activities. Therefore, it is necessary to improve supporting policies and mechanisms to support innovation management for enterprises with S\&T activities in the direction of facilitating and promoting innovation activities, researching, 
development, application, technology transfer, commercialization of research results, digital transformation of enterprises through refresher courses, short-term training courses.

Secondly, developing a training program for enterprises should be conducted after understanding the characteristics, resources and needs of the target audience; at the same time, fostering and training programs and documents need to be consistent with support policies and support programs of the Government in each period.

Thirdly, the form of organization can be conducted in a variety of ways. It is possible to organize centralized training for businesses, or at businesses, or it can be a combination of online form with online training form (online) to meet the growing requirements of businesses.

Fourthly, the training contents need to be coordinated and linked with universities, research organizations and S\&T service organizations. The contents aim at the relationship between innovation goals and the overall strategic goals of enterprises, supporting businesses to improve their commercialization skills, helping businesses understand the regulations and policies on the innovation management system, providing information for businesses to innovate through digital transformation and technology application for smart production.

Fifth, in the process of developing a fostering and training program for enterprises with scientific and technological activities, it is necessary to pay attention to the context of the business, the leadership and management style of the business owner, the state of enterprise planning and the activities required to establish an innovation system of the enterprise, with particular attention to efficiency and performance improvement for the innovation system of the enterprise.

In addition, in addition to determining the objectives, training subjects, and outcomes, in the process of designing training programs for enterprises with S\&T activities, it is necessary to pay attention to factors such as the number of specialists to/module, order of modules/ specialization, time, method, form of training and the trainers and units to coordinate in implementing the training.At the same time, after completing the training course for businesses, it is also necessary to evaluate whether the program is as effective as the set goals or not, thereby giving lessons learned and appropriate adjustments can be made.

\section{Acknowledgement: None}

Conflict of Interest: None

\section{Source of Funding: None}

\section{REFERENCES}

1. Allan Afuah (2012), Managing the Innovation \& Creativity Process-Vietnamese Version, National Economics University Publishing House.

2. Alexandru Ionescu and Nicoleta Rossela Dumitru (2015). The role of innovation in creating the company's competitive advantage, Ecoforum 4(1). p.99-104.

3. Cunfang, LiaDanping and LibMeiDonga (2019), The spillage effect of the transfer behavior of coal resource-exhausted enterprises and science and technology projects, Resources Policy, Volume 62, August 2019, Pages 385-396.

4. Chatri Sripaipan and Yada Mukdapitak (2007), Thailand's STI Policy and System towards Knowledgebased Society, Presented at the 5th Ministerial Meeting on Cooperation in Science and Technology between Thailand and Vietnam

5. ESCAP (1989), Technology Atlas Project- A framework for technology based development, ThaiLand

6. European Commisstion (EC, 1995), Green Paper on Innovation, EU

7. French Larousse Dictionary (2002), Vietnamese version, Hanoi, Vietnam.

8. General Department of Taxation (2021), Report on tax payment of enterprises, Ministry of Finance, Vietnam

9. Government (2013), Decree 13/2019/ND-CP on S\&T enterprises, Hanoi, Vietnam

10. Ha Minh Hiep (2019), Smart production in the industrial revolution 4.0, National Political Publishing House Truth, Vietnam. 
Nguyen Hии Xuyen et.al. Innovation management of enterprises with scientific and technological activities of some Asian countries and lessons for Vietnam

11. ISO 56002 (2019), Innovation management Innovation management system-Guidance, https://www.iso.org/standard/68221.html

12. Johnston R (1996), Technical Progress and Innovation, Published By: Oxford University Press.

13. Joseph Schumpeter (1934), An Inquiry into Profits, Capital, Credit, Interest, and the Business Cycle, Harvard Economic Studies.

14. Katz M (2007), Mergers and innovation, Antitrust Law Journal No. 1/2007

15. Kowang (2015), Innovation Management and Performance Framework for Research University in Malaysia. International Education Studies, 8(6): 32-44.

16. National Assembly of China (2015), Law on Promoting the Transformation of S\&T Achievements, Beijing, China

17. National Assembly (2017), Law on Technology Transfer, Vietnam.

18. National Assembly (2013), Law on Science and Technology, Vietnam

19. National Assembly (2020), Enterprise Law, Vietnam

20. National Assembly (2008), Law on High Technology, Vietnam

21. Nguyen Huu Xuyen, Nguyen Thi Lan Huong (2016), The Applying of Science and Technology into the Production: Thailand's Experience and Lessons For Vietnam, International Journal of Science and Research (IJSR), Volume 6 Issue 4, April 2017.

22. Nguyen Huu Xuyen (2018), Solution to Improve Level and Capacity of Technology in the Vietnam's Enterprises, International Journal of Business and Management Invention (IJBMI), Volume 7 Issue 6 Ver. I, Jun. 2018.

23. National Science Technology and Innovation Policy Office (2014), Overview of Thailand's Science, Technology and Innovation Policy, Ministry of Science and Technology, Thailand

24. National Administration of Science and Technology Information (NASATI, 2018), Research results on innovation in Vietnamese enterprises, Science and Technology Publishing House.

25. National Administration of Science and Technology Information (NASATI, 2009), National Innovation System of China, Hanoi.

26. Ministry of Finance and Ministry of Science and Technology (2016), Circular No.
12/2016/TTLT-BKHCN-BTC guiding the content of spending and management of enterprise science and technology development funds, Hanoi, Vietnam.

27. OECD/Eurostat (2005). Oslo Manual: Guidelines for Collecting and Interpreting Innovation Data, 3rd Edition. The Measurement of Scientific and Technological Activities. OECD Publishing. Paris.

28. OECD (2011), Country Profile of Innovation in Thailan, Review of Innovation in Southeast Asia.

29. OECD (2018). Promoting innovation in established SMEs. Parallel session 4. SME Ministerial Conference. 22-23 February 2018. Mexico City.

30. Office of the Central Committee of the Communist Party of China (2015), Plan for the Implementation of Reform for the Promotion of Scientific and Technological Institutions, Beijing, China.

31. Prime Minister (2015), Decision No. 19/2015/QD-TTg of the Prime Minister stipulating criteria for identifying high-tech enterprises, Hanoi, Vietnam

32. Philosophical Dictionary of the Soviet Union (1975), Vietnamese version, Vietnam Truth Publishing House.

33. Vietnam-Finland Innovation Partnership Program (IPP, 2013), Innovation \& Entrepreneurship Training Manual, Hanoi, Vietnam.

34. Vu Cao Dam (2008), Scientific Research Methodology, Science and Technology Publishing House.

35. UNCTAD (2015), Science, Technology \& Innovation Policy Review, New York and Geneva, 2015.

36. William R. Kerr (2016), Innovation and Business Growth. Moving to the Innovation Frontier. WPZ Research Frontier No. 3 (2016). p.41-53.

How to cite this article: Nguyen Huu Xuyen, Tran Vu Tuan Phan, Tran Xuan Bach et.al. Innovation management of enterprises with scientific and technological activities of some Asian countries and lessons for Vietnam. Galore International Journal of Applied Sciences \& Humanities. 2022; 6(1): 7-17. DOI: https:// doi.org/10.52403/gijash.20220102 